\title{
As escolas radiofônicas anunciam uma educação regionalista
}

\author{
Kelma Fabíola Beltrão de Souza \\ Doutora em Teoria e História da Educação pela Universidade Federal de Pernambuco (UFPE). \\ Atualmente faz estágio pós-doutoral na mesma instituição. \\ E-mail: beltraokelma@yahoo.com.br
}

Resumo: Este artigo teve como objetivo mostrar o que foi regularmente anunciado nas escolas radiofônicas do Movimento de Cultura Popular (MCP) de Recife (1960-1964) por meio do seu material pedagógico, o Livro de leitura para adultos. Pretendeu-se também mostrar os acontecimentos discursivos presentes na criação do MCP: questões sobre municipalização enfatizadas na Lei de Diretrizes e Bases da Educação; a "adequação regional" proposta por Anísio Teixeira e a criação do Centro Regional de Pesquisas Educacionais de Pernambuco, dirigido por Gilberto Freyre; e a formulação de uma identidade nacional, com características regionais. Observando o que foi regular no discurso, como nos orienta Michel Foucault, o estudo concluiu que o Livro de leitura para adultos das escolas radiofônicas traz ecos das práticas regionalistas almejadas por Gilberto Freyre, ou seja, com a constituição genuína e autêntica de um povo que precisava ser alfabetizado.

Palavras-chave: escolas; escolas radiofônicas; movimento; cultura; regionalista.
Abstract: This article aimed to show what was regularly announced in radio schools of the Movimento de Cultura Popular (MCP - Popular Culture Movement) in Recife (1960-1964), through its pedagogical material, the Reading book for adults. It also sought to show the discursive events surrounding the creation of the MCP: questions on municipalization emphasized in the Law of Guidelines and Bases of Education; the "regional adequacy" proposed by Anísio Teixeira and the creation of the Regional Center of Educational Researches of Pernambuco, directed by Gilberto Freyre; and the formulation of a national identity, with regional characteristics. By observing what was regular in the speech, as Michel Foucault guides us, the study concluded that the Reading book for adults of the radio schools echoes the regionalist practices aimed by Gilberto Freyre, that is, a genuine and authentic constitution of a people who needed to be literate.

Keywords: schools; radio schools; movement; culture; regionalist. 


\section{INTRODUÇÃO}

Muitos dos estudos dos campos historiográfico e sociológico que analisam as questões sobre a educação entre os anos de 1957 e $1964^{1}$ trazem ideias, temas, movimentos e personagens que evidenciam a originalidade e pioneirismo nas ações educacionais no Recife. Inseridas neste contexto, estão abordagens sobre o Movimento de Cultura Popular do Recife (MCP, 1960-1964).

Flávio Brayner², numa reflexão sobre esses estudos, afirmou que comumente são abordados o "povo como categoria histórica" e a "crise de hegemonia", mas talvez "as coisas não sejam exatamente assim!”. Para ele, o MCP foi constituído com a intenção de atender às expectativas de uma identidade nacional, de modo que muitos, desejosos de constituir essa identidade, vão, também, idealizar um povo. Brayner $^{3}$ comentou ainda que um dos impasses dessas interpretações sobre o MCP é que elas não conseguem articular os anos 1920 aos anos 1950, provocando um entendimento imaginário do movimento, entrecortado pela questão da originalidade.

A partir desses aspectos, tentando construir outra narrativa sobre o MCP do Recife, seguimos as orientações de Michel Foucault ${ }^{4}$ sobre a pesquisa: desmontamos o livro, o artigo, e significamos os vários acontecimentos discursivos que os textos trazem. Já no campo historiográfico, tentamos entender o discurso "com certa regularidade", "pela repetição regular de determinados enunciados", como sugeriu Durval Muniz de Albuquerque Júnior ${ }^{5}$.

Dessa forma, foi importante nos determos no documento próprio do MCP, o Livro de leitura para adultos ${ }^{6}$ (das experiências com as escolas de rádio), como lugar de pesquisa para a feitura da narrativa. Procuramos tratar este documento como algo relacionado às ações e aos acontecimentos da instituição MCP. Buscamos compreender o discurso enquanto prática, num esforço de tentar captar o estar, o que é dito e o que é feito, admitindo as "formações discursivas" e colocando de lado as "unidades tradicionais do livro e da obra"

Os acontecimentos registrados no período em questão gravitam em torno do Projeto de Lei no 2.222/19579 (que resultou na Lei de Diretrizes e Bases da Educação, de $1961^{10}$ ) e das ideias e ações de Anísio Teixeira - em especial em relação à criação, em 1957, do Centro Regional de Pesquisas Educacionais de Pernambuco (CRPE, também chamado de Centro Regional de Pesquisas Educacionais do Recife, ou apenas CRR), dirigido por Gilberto Freyre. Anísio Teixeira, pensando numa educação de adequação regional, e Gilberto Freyre, com suas práticas regionalistas, em certo sentido ajudam na composição do MCP, que tece uma identidade nacional evidenciando dimensões educativas regionais - não apenas no sentido de ressaltar as características de um povo e de uma cultura local, mas também de evidenciar, idealizar e constituir estes aspectos, como fez Freyre com seu regionalismo.

Para isso, apresentamos a seguir uma breve explicação sobre o regionalismo gilbertiano (embasado nas ideias regionalistas de Gilberto Freyre) e o MCP, depois sobre as Escolas Radiofônicas e, posteriormente, sobre o que foi anunciado recorrentemente no Livro de leitura para adultos (material didático do MCP) ${ }^{11}$.
1. FÁVERO, Osmar (org) Cultura popular, educação popular: memória dos anos 60. 2. ed. Rio de Janeiro: Graal, 1983: SAVIANI, Dermeval. Escola e democracia. 41. ed. São Paulo: Autores Associados, 2009; SOUZA, João Francisco de. Uma pedagogia da revolução: a contribuição do governo Arraes (1960-64) à reinvenção da educação brasileira. São Paulo: Cortez: Autores Associados, 1987; WEBER, Silke. Política e educação: - Movimento de Cultura Popular no Recife. Revista de Ciências Sociais Rio de Janeiro, v. 27 n. 2, p. 233-262, 1984.

2. BRAYNER, Flávio. O MCP e a invenção do "povo". Revista Continente, Recife, ano 10, n. 113, p. 54,8 maio 2010, p. 54

3. BRAYNER, Flávio. O elixir da Redenção: o Movimento de Cultura Popular do Recife (1960-1964). In: STRECK, Danilo; ESTEBAN, Maria Teresa (org.). Educação popular: lugar de construção social coletiva. Petrópolis: Vozes, 2013. p. 188-202

4. FOUCAULT, Michel. A arqueologia do saber. 7. ed. Rio de Janeiro: Forense Universitária, 2009.

5. ALBUQUERQUE JUNIOR Durval Muniz de. A invenção do Nordeste e outras artes. 4. ed. São Paulo: Cortez, 2009, p. 35

6. LIVRO de leitura para adultos. In: MOVIMENTO de Cultura Popular: memorial. Recife: Fundação de Cultura da Cidade do Recife, 1986. (Coleção Recife, v. 49).

7. FOUCAULT, op. cit., p. 68.

8. Ibidem, p. 89.

9. BRASIL. Projeto de Lei $n^{\circ} 2.222$, de 11 de fevereiro de 1957. Câmara dos Deputados, Brasília, DF, 10 dez. 2006. Disponível em: https://www.camara. leg.br/proposicoesWeb/ fichadetramitacao?idProposicao $=201132$. Acesso em: 14 mar. 2019. 
10. BRASIL. Lei ${ }^{\circ} 4.024$, de 20 de dezembro de 1961 . Fixa as Diretrizes e Bases da Educação Nacional. Diário Oficial da União: seção 1, Brasília, DF, ano 99, p. 11.429, 27 dez. 1961.

\section{LIVRO..., op. cit.}

12. BRASIL, 1961

13. PRESENÇA na mídia: matérias em jornais ou revistas de divulgação. Biblioteca Virtual Anísio Teixeira, Salvador, [2000?]. Disponível em: http://www.bvanisioteixeira.ufba.br/midia.htm. Acesso em: 14 mar. 2019; TEIXEIRA, Anísio Spínola. Educação não é privilégio. 7. ed. Rio de Janeiro: Editora UFRJ, 2007.

14. Ver em: FREYRE, Gilberto. Sugestões para uma nova política no Brasil: a rurbana. Revista Brasileira de Estudos Pedagógicos, Rio de Janeiro, v. 27, n. 65, p. 65-82, 1957b; FREYRE, Gilberto. Palavras às professoras rurais do Nordeste. Revista Brasileira de Estudos Pedagógicos, Rio de Janeiro, v. 28, n. 68, p. 40-50, 1957a; FREYRE, Gilberto. Região, pesquisa social e educação. Revista Brasileira de Estudos Pedagógicos, Rio de Janeiro, v. 29, n. 69 p. 31-41, 1958b.

15. BRAYNER, 2010, p. 54.

\section{ALBUQUERQUE} JUNIOR, 2009, p. 213.

17. Entre os movimentos contemporâneos que o autor cita, havia no Recife o MCP.

18. FREIRE, Paulo. A propósito de uma adminis tração. Recife: Universidade do Recife, 1961, p. 7. Freire trabalhava como assessor do reitor da Universidade do Recife (atual Universidade Federal de Pernambuco - UFPE) e fez uma espécie de relatório sobre a gestão do reitor João Alfredo.

\section{O REGIONALISMO GILBERTIANO E O MOVIMENTO DE CULTURA POPULAR}

A partir de 1957, discutiam-se no Congresso Nacional, através do Projeto de Lei $n^{\circ}$ 2.222/1957, as diretrizes que deveriam orientar a educação no Brasil, o que resultou na Lei de Diretrizes e Bases da Educação (Lei nº 4.024/1961). Um dos aspectos ressaltados nesses dispositivos foi a cobrança da responsabilidade do município com a educação, orientando-o a chamar a população escolar para a matrícula na escola primária ${ }^{12}$.

Também em 1957, o então diretor do Instituto Nacional de Pesquisas Educacionais (Inep), Anísio Teixeira, pleiteava a necessidade de uma educação orientada para a municipalização, no sentido de haver uma adequação regional. A instituição de uma escola primária, para Anísio, estava relacionada à região e ao local ${ }^{13}$. No Recife, a investida de Anísio Teixeira ocorreu quando foi organizado o CRPE, em 1957, dirigido por Gilberto Freyre. O centro teve por objetivo promover a educação nessa capital, com base numa educação científica e regional, através de estudos, pesquisas, seminários e da escola.

Nesse período, Freyre ${ }^{14}$ percebeu, como exímio conciliador, que suas ideias regionalistas poderiam ser harmonizadas com as questões educacionais e pleiteou a necessidade de alfabetizar a população. Ao tecer certa ideia de educação (usando seu regionalismo de bases sociológicas), concebeu-a com contornos peculiares: pensou um sistema educacional com práticas que conciliassem os valores urbanos e rurais; com uma professora com habilidade de "extrair" das populações a sobrevivência de "culturas primitivas" e as ajudasse a despertar o gosto pelo que é seu; um ato de ensinar que levasse em conta o aproveitamento das "superstições" da população e, em contrapartida, desprezasse outras. Uma educação a seu modo, considerando que as populações analfabetas (em especial do Nordeste) guardavam um estoque de originalidade: a nossa brasilidade!

Foi em torno dessa ideia de "preservação cultural" que, em 1960, foi organizado o MCP. Esse movimento se constituiu no sentido de atender às perspectivas de fabricar uma identidade nacional, idealizando, também, um povo e sua cultura $^{15}$. De certa forma, os movimentos de cultura popular em geral, outros movimentos e instituições dão prosseguimento ao trabalho dos intelectuais dos anos 1930 de produzir uma cultura nacional-popular ${ }^{16}$ - inclusive na feitura de uma identidade nacional, tecida regionalmente por Gilberto Freyre.

O MCP, como "alongamento" das ideias regionalistas de Freyre, foi comentado por Paulo Freire (que, na época, prestava serviços ao CRPE e era um dos sócios-fundadores do MCP), quando afirmou:

Em 1926, no Manifesto Regionalista, apresentado ao Congresso que pioneiramente o Movimento Regionalista levou a efeito no Recife - Movimento de que muitas de suas sugestões vêm sendo realizadas e de que alguns movimentos atuais ${ }^{17}$, em não pouco de seus fundamentais aspectos são alongamentos daquele, dizia Mestre Gilberto Freyre: "Nosso movimento não pretende senão inspirar uma nova organização do Brasil [...]"18. 
As ideias regionalistas de Freyre já se evidenciavam, no tempo e no espaço, por meio de suas principais obras, bem como de todo seu arrojo em conferências, palestras, artigos de jornais e outras funções desenvolvidas. Essas ideias também estavam presentes, como já dissemos, no CRPE. Por sua vez, muitos dos sócios-fundadores do MCP participaram do CRPE (ao mesmo tempo ou depois de o terem deixado). Paulo Freire, Anita Paes Barreto e Maria Antônia Mac Dowell participaram como conferencistas, palestrantes, debatedores e formuladores de projetos. Paulo Rosas e Josina Godoy foram funcionários do Centro. No MCP, eles foram responsáveis por várias ações no âmbito educacional ${ }^{19}$, facilitando, assim, o alongamento do regionalismo gilbertiano no MCP.

\section{AS ESCOLAS RADIOFÔNICAS}

Quando o MCP foi organizado, não existiam escolas municipais. Toda a rede escolar municipal primária do Recife, organizada desde 1894, tinha sido transferida para o estado ${ }^{20}$. Tanto é que, em 1958, Aderbal Jurema (então Secretário de Educação de Pernambuco) relatou que Recife era o único município que não tinha escolas primárias ${ }^{21}$.

Foi esse o panorama que Miguel Arraes encontrou ao assumir a prefeitura do Recife: inexistência de escolas municipais e de orientações de dispositivos legais (como mostramos anteriormente). As investidas de Arraes na educação ocorreram através do MCP (1960), oficializado em 1961. O Movimento teve ações voltadas para educação (escola primária; escolas radiofônicas; centros de cultura), teatro, cinema etc.; e nele atuavam intelectuais, professores, escultores, estudantes. Desses, alguns tiveram ações mais efetivas como sócios-fundadores ou dirigentes ${ }^{22}$. No plano de alfabetização de adultos, a experiência do MCP noticiada pela imprensa durante o ano $1961^{23}$ foi a das escolas radiofônicas.

As escolas radiofônicas funcionaram nos espaços físicos já cedidos pela população para escolas diurnas, como clubes e associações. Por meio de aparelhos de rádio, também doados pela comunidade, os programas eram transmitidos à noite pelas rádios Clube de Pernambuco e Continental, enquanto, nas escolas, os monitores auxiliavam na orientação a respeito dos conteúdos tratados no programa. Quando foi inaugurado o projeto educacional de alfabetização de adultos por meio das escolas radiofônicas (coordenado por Paulo Freire), já existiam 50 escolas trabalhando com educação de base, cada uma com 20 a 40 alunos $^{24}$. A imprensa local noticiou a inauguração das escolas ${ }^{25}$, relatando que a primeira aula transmitida pelo rádio foi lecionada por Josina Godoy, supervisora da equipe de educação radiofônica. Pensando num material pedagógico que contemplasse os contextos locais, Josina Godoy, Norma Coelho e Mércia Albuquerque prepararam um manual de leitura para adultos, em 1961, que foi publicado em 1962 como Livro de leitura para adultos ${ }^{26}$.

Ainda na inauguração do projeto de Alfabetização de Adultos, através das escolas radiofônicas, a equipe central, que comandava a transmissão e elaborou
19. CADERNOS REGIÃO E EDUCAÇÃO. Recife: Centro Regional de Pesquisas Educacionais do Recife, v. 3, n. 3, jun. 1963; CENTRO REGIONAL DE PES QUISAS EDUCACIONAIS DO RECIFE. Educação e região: problemas de política e administração escolares no Nordeste brasileiro. Recife: CRPE, 1960.

20. EGITO, Juscelino Lima. As primeiras escolas e a formação da rede escolar pública municipal (1894. 1929). In: RECIFE. Recife 100 anos de escola pública municipal. Recife: Prefeitura da Cidade, 2000, p. 26.

21. JUREMA, Aderbal. A situação do ensino primário em Pernambuco. In: CENTRO REGIONAL DE PESQUISAS EDUCACIONAIS DO RECIFE. Educação e região: problemas de política e administração escolares no Nordeste brasileiro. Recife: CRPE, 1960, p. 68.

22. MOVIMENTO de Cultura Popular: memorial. Recife: Fundação de Cultura da Cidade do Recife, 1986. (Coleção Recife, v. 49).

23. PLANO de educação de adultos, do MCP. Diário de Pernambuco Recife, n. 22, 26 jan. 1961. Primeiro Caderno, p. 3 Disponível em: http:// memoria.bn.br/DocReader/029033_14/8018. Acesso em: 18 mar. 2019; 40 ESCOLAS do MCP até o fim deste mês. Diário de Pernambuco, Recife, n. 58, 12 mar. 1961. Primeiro Caderno, p. 11. Disponível em: http:// memoria.bn.br/DocReader/029033_14/8851. Acesso em: 18 mar. 2019; NOVAS escolas do MEC e audiência de Arraes nos bairros. Diário de Pernambuco, Recife, n. 69, 25 mar. 1961. Segundo Caderno, p. 3. Disponível em: http://memoria.bn.br/ DocReader/029033_14/9117. Acesso em: 18 mar. 2019; EDUCAÇÃO pelo rádio: MCP. Diwário de Pernambuco, Recife, n. 154, 9jul. 1961. Primeiro Caderno, p. 6. Disponível em: http:// memoria.bn.br/DocReader/029033_14/11102. Acesso em: 18 mar. 2019. 
24. MOVIMENTO..., op. cit.

25. INAUGURADAS, ontem, as primeiras 50 escolas radiofônicas no Recife. Diário de Pernambuco, Recife, n. 208, 12 set. 1961 Primeiro Caderno, p. 3 Disponível em: http:// memoria.bn.br/DocReader/029033_14/12339 Acesso em: 18 mar. 2019.

26. MOVIMENTO..., op. cit. COELHO, Germano. MCP: história do Movimento de Cultura Popular. Recife: Ed. do Autor, 2012

27. INAUGURADAS...,

op. cit.

28. LIVRO..., op. cit. Ver mensagem para o aluno ao final do livro (n. p.).

29. GODOY, Josina; PORTO, Norma. Apêndice. In: MOVIMENTO de Cultura Popular: memorial. Recife: Fundação de Cultura da Cidade do Recife, 1986. (Coleção Recife, v. 49). p. 199.

30. BRAYNER, Flávio. Paulofreireanismo: instituindo uma teologia laica? In: REUNIÃO NACIONAL DA ANPED, 37., 2015, Florianópolis. Anais [...]. Rio de Janeiro: Anped, 2015. Trabalho apresentado no GT6. Brayner, nesse texto, refere-se ao método Paulo Freire.

Como a prática usada para elaboração desse método

foi a mesma (a retirada das palavras geradoras do contexto), pontuamos as mesmas observações a seu respeito.

31. LIVRO..., op. cit., p. 78. 32. Ibidem, n. p. Lição 19.

33. Ver observações de Albuquerque Junior (2009) sobre Pernambuco e Recife como local unificador do discurso gilbertiano.

34. FREYRE, 1958a, p. 33. o manual, afirmou que este foi feito "de acordo com as últimas aquisições da Unesco (Organização das Nações Unidas para Educação, a Ciência e a Cultura) em educação de adultos" ${ }^{27}$. No final do próprio Livro de leitura, Josina Godoy e Norma Porto, as autoras, relataram que a elaboração do livro foi feita partir das as "experiências publicadas nas revistas da Unesco, organização mundial de educação e cultura" ${ }^{28}$.

Sobre os assuntos abordados no livro (temas de interesse dos alunos), Josina Godoy e Norma Porto $^{29}$ registraram que o MCP preferiu:

partir de zero, utilizando experiência acumulada durante três meses de pesquisas, nas zonas populares do Recife.

Das longas conversas com o povo, surgiram os centros de interesse fundamentais, representativos das ideias básicas a serem debatidas em classe. [...] Eram os temas que constituíam o universo de preocupação do adulto, no Recife.

O processo de escolha dos textos e das palavras no Livro de leitura foi desenvolvido por intelectuais "autorizados" a retirar as "palavras do contexto" e a "devolvê-las sob uma formatação crítica". Esse caminho parte do pressuposto de que "a consciência do outro é insuficiente, precária ou ingênua"

Na observação do que foi constante no discurso, no sentido de perceber as regularidades traçadas pelas práticas do MCP por meio do Livro de leitura para escolas radiofônicas, constatamos que se buscou, principalmente, constituir uma identidade nacional, para tecer, sobretudo, uma educação de dimensão regionalista, especialmente formulada a partir das ideias de Freyre.

\section{UM LIVRO DE LEITURA PARA ENSINAR SOBRE A REGIÃO NORDESTE}

Josina Godoy e Norma Porto ${ }^{31}$ anunciaram que o livro traria formas de "ensinar a ler que pudessem interessar ao homem e à mulher do Nordeste, cansados da luta diária pela sua sobrevivência e a de seus filhos". O Nordeste era a região, Pernambuco o estado, e Recife o município que uniam tudo isto. O "cidadão do Recife" ${ }^{2}$ precisava, para sua alfabetização, de experiências que retratassem suas condições. A alfabetização sobe o morro, vai para a periferia, entra nos alagados e chega aos mocambos do Recife $^{33}$ - pois, como disse Freyre: "Recife, mais que outra qualquer cidade do Brasil com tradições de responsabilidade intelectual, vem-se distinguindo, há anos, ao destacar como necessário à melhor articulação da vida ou da cultura brasileira" ${ }^{34}$.

Ao anunciar Recife, Pernambuco e o Nordeste, o Livro de leitura para adultos traz padrões silábicos, palavras, frases e pequenos textos acompanhados de ilustrações. A estratégia foi unir a fotografia ou pintura, aglutinando outras formas de discurso sobre a região e despontando também vocações de outros artistas que evidenciam o Nordeste. São fotos dos moradores, da cidade do Recife, de obras de arte, de pinturas, e também ilustrações de Saraiva, Elijah Von Sohsten, 
Gilvan da Silva, Robert Chorovsky, Johannes Friese, Cleto e Aberlado da Hora. As autoras unem padrões silábicos e textos àqueles que pintam e fotografam, construindo, assim, uma dada ideia de Nordeste $^{35}$.

Comumente, Freyre trazia pinturas e desenhos para acompanhar seus textos, imagens que compartilhavam da mesma ideia regional ${ }^{36}$. Freyre, ainda em 1941, reclamou sobre a falta de artistas que se dedicassem a pintar a região ${ }^{37}$.

O Nordeste também foi retratado no livro com relação às injustiças da seca no sertão: "O sertanejo vive no sertão: sua vida é árdua. Seu voto deve servir para mudar sua sorte" ${ }^{8}$; "A cena da seca do sertão é dramática. Mas também na cidade a falta d'água é um drama. Agora os nordestinos tentam, com fé, resolver todos os seus dramas" 39 .

Nas lições sobre o sertão, a seca foi colocada como um problema social: o desamparo do homem, as dificuldades de plantio, a falta d'água e a destruição da lavoura são alguns dos motivos que o levam à cidade. Problemas sociais que podem ser resolvidos através do voto. Ao construir uma ideia de Nordeste, Freyre desvencilhou-se das questões naturais, como a seca, e inseriu fatos históricos. A seca aparece só entre as "consequências morais e sociais". Como assinalou Albuquerque Junior ${ }^{40}$, para Freyre, "são os fatos históricos e, principalmente, os de ordem cultural que marcariam sua origem".

No Livro de leitura utilizado nas experiências educativas com o rádio, a história da região Nordeste tem heróis: Joaquim $\mathrm{Nabuco}^{41}$ e Lampião ${ }^{42}$. Os fatos históricos ganham destaque: a abolição da escravidão ${ }^{43}$, a Batalha dos Guararapes e a construção de Brasília, capital feita com ajuda dos nordestinos ${ }^{44}$. A região tem também a presença de instituições como a Companhia Hidroelétrica (CHESF) ${ }^{45}$ e a Superintendência para o Desenvolvimento do Nordeste (Sudene) ${ }^{46}$, que auxiliam no seu desenvolvimento. Foram os heróis e os fatos que fizeram esse Nordeste ser diferente: "Pernambuco também tem sua herança de glórias. Os heróis pernambucanos venceram o invasor holandês" ${ }^{\prime 4}$.

O Livro de leitura mostrou que a origem da nação está no Nordeste. A história de Pernambuco mostra que a luta que se travou contra os holandeses foi "o primeiro surto de nacionalismo no Brasil" "48. É o início da nossa nação, da nossa brasilidade. A nação está em Pernambuco, e seu povo também - esse povo que precisa ser "alfabetizado", mas tem como características sua luta e seu empenho diante das dores.

O homem nordestino "lutador", no passado e no presente, "ajudou o desenvolvimento do sul", então "o homem do Nordeste pede justiça" Gilberto Freyre, há um Nordeste injustiçado, sem valor diante da economia do "sul industrial" ${ }^{0}$. Mas esse Nordeste desvalorizado, em contrapartida, tem aspectos genuínos: "os velhos, as mulheres, [e] os analfabetos rurais" guardam um conhecimento "que é mais genuinamente brasileiro na cultura brasileira; o que é mais raiz nessa cultura" "51. Uma civilização que, pela sua originalidade, se destaca diante de outras. Ela exala o conceito de "povo" em sua essência: na música, nos folguedos, nas festas, nas comidas, na arte formadora de uma cultura única. Essa cultura, por sua vez, traduz os valores reais da região.

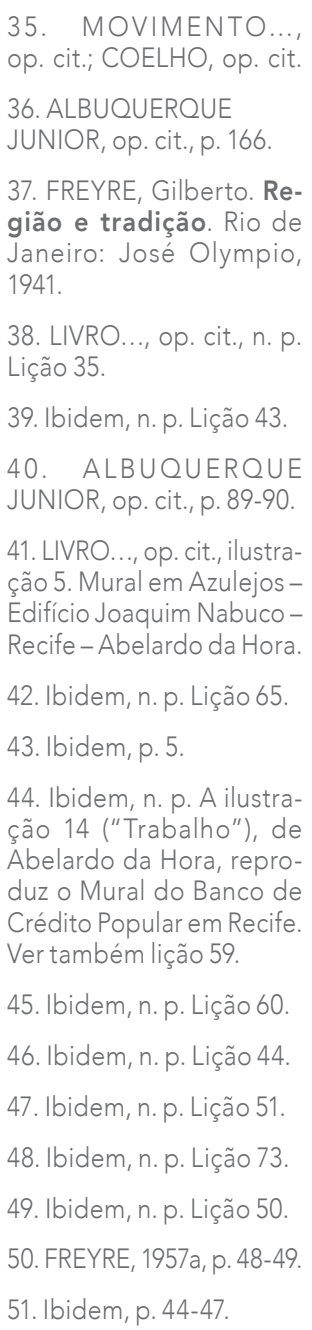


52.ALBUQUERQUE JUNIOR, op. cit., p. 93.

53. Características evidenciadas em várias lições do Livro de leitura para adultos (LIVRO..., op. cit.). Ver lição 44.

54. Ibidem, n. p. Lição 17. A palavra mocambo está presente nas lições $14,15,16$, $23,24,33$. Ver ainda as fotografias "Casa e Mocambo" (ilustração 2), de Saraiva, e "Mocambos" (ilustração 3), de Elijah Von Sohsten (Ibidem, n. p.).

55. GOMINHO, Zélia. Veneza Americana x Mucambópolis: o Estado Novo na cidade do Recife (décadas de 30 e 40). 1997. Dissertação (Mestrado em História) - Universidade Federal de Pernambuco, Recife, 1997, p. 36.

56. Ibidem, p. 37.

57. LIVRO..., op. cit., ilustração 3.

58. Ibidem, n. p. Lição 71.

59. Ibidem, n. p. Lição 73.

60. Ibidem, n. p. Lição 54 .

61. ALBUQUERQUE JUNIOR, op. cit.
Essa evidência (dos romancistas e de Freyre) dada ao povo, seus temas e expressões fez com que as camadas populares se aproximassem de um Nordeste desejado $^{52}$. O povo, que é possuidor de uma cultura enraizada, autêntica e essencial, foi o que o Livro de leitura para adultos do MCP enfatizou. Buscava-se, também, despertar nessa população que estava sendo alfabetizada uma sensação de identificação e pertencimento. Evidenciaram-se, assim, sua cultura, seus assuntos, suas danças, suas músicas e outras formas de expressão. Esse povo traz uma cultura tradicional: batucada, samba, pastoril, quadrilha, coco, ciranda, frevo, maracatu etc. São essas danças e músicas que compõem a sonoridade e o bailado do Nordeste, uma região com a arte de produzir sabores, gostos e cheiros de peixe, canjica e pamonha. Um Nordeste em que o homem pode fazer com as suas próprias mãos a cerâmica e o artesanato. Uma cultura original que deve ser valorizada, porque é única ${ }^{53}$.

As lições do Livro de leitura para adultos mostram que até a moradia desse povo é única: o mocambo, "a casa do povo do alagado" ${ }^{4}$. Para Zélia Gominho ${ }^{55}$, o olhar antropológico de Freyre fez com que ele percebesse "o valor cultural do mocambo, a sabedoria popular enquanto arte de trançar e de motivo para congregar a família, a comunidade, num esforço comum”. Para Freyre, o mocambo ideal seria aquele higienizado e em terreno saneado, entretanto "os mocambos em que pousava seu olhar poético e romântico eram os do meio rural e os do litoral da beira da praia, aquela pitoresca imagem do mar, o mocambo e o coqueiro" ${ }^{56}$. No Livro de leitura para adultos, a fotografia "Mocambos" (ilustração 3), de Elijah Von Sohsten ${ }^{57}$, retrata essa moradia diante da praia e dos coqueiros, imagem que se une ao texto na composição de um Nordeste romanceado.

Mas essa cultura também se constitui pela conciliação, pela combinação do que nos parece mais adverso: a junção das três raças (o português, o índio e o negro $)^{58}$, em um povo que se formou "sem preconceito de cor" ${ }^{59}$. A harmonia foi também o modo como o MCP se constituiu, pois foi um movimento (uma instituição) capaz de agregar diversos aspectos: "O MCP congrega homens de todas as raças, de todas as opiniões, de todas as religiões, para um fim comum: a elevação do nível cultural do povo" ${ }^{\circ 0}$. Juntar o adverso ou o que parece estranho e dotá-los com tons de naturalidade era uma das principais posturas utilizadas por Freyre ${ }^{61}$.

A exaltação da cultura do povo e dos seus valores regionais e tradicionais presente no Livro de leitura para adultos do MCP serviu na educação de adultos para ensinar as "letras" aos analfabetos mas, principalmente, para ajudar a constituir uma ideia de civilização genuína, que habitava a região Nordeste e "precisava” ser educada.

\section{CONSIDERAÇÕES FINAIS}

Ainda que o que pontuamos seja uma versão histórica, é importante ressaltar que este panorama foi elaborado por meio de documentos, da aberturas e do 
desmonte de livros e textos, na tentativa de entender o que era recorrente no discurso do Livro de leitura para adultos do MCP, como nos orientou Foucault.

Percebemos que a experiência do MCP contemplou locais sem acesso à educação, atendeu adultos analfabetos e usou o rádio como meio acessível, aspectos importantes para alterar a educação no Recife.

Sobre o que foi regularmente anunciado pelo MCP, a partir das experiências das escolas radiofônicas e de seu material pedagógico (Livro de leitura), ressaltamos o que nos falou Brayner e Albuquerque Junior a respeito dessa investida: foram vários grupos que se colocaram a responder qual era a "nossa" identidade, nacionalmente falando.

O MCP foi uma instituição que assim se fez e que respondeu a esse questionamento quando ressaltou, também, ideias regionalistas gilbertianas, no sentido de valorizar, na prática, a existência de uma civilização original no Nordeste, urdida a partir da decadência da cultura canavieira, exaltando essa civilização. Um Nordeste construído a partir de inserção de fatos históricos, da conciliação, de elogios à tradição e de experiências que evidenciavam a cultura original e autêntica de um povo, continuando, assim, perspectivas já sinalizadas por intelectuais em outras épocas.

Nesse contexto, o Livro de leitura para adultos, material pedagógico das escolas radiofônicas, evidenciou recorrentemente o Nordeste: região de um povo que precisava ser educado, mas que também tem uma cultura com características originais e autênticas, que não devem ser desprezadas.

\section{REFERÊNCIAS BIBLIOGRÁFICAS}

40 ESCOLAS do MCP até o fim deste mês. Diário de Pernambuco, Recife, n. 58, 12 mar. 1961. Primeiro Caderno, p. 11. Disponível em: http:/ / memoria. bn.br/DocReader/029033_14/8851. Acesso em: 18 mar. 2019.

ALBUQUERQUE JUNIOR, Durval Muniz de. A invenção do Nordeste e outras artes. 4. ed. São Paulo: Cortez, 2009.

BRASIL. Lei nº 4.024, de 20 de dezembro de 1961. Fixa as Diretrizes e Bases da Educação Nacional. Diário Oficial da União: seção 1, Brasília, DF, ano 99, p. 11.429, 27 dez. 1961.

BRASIL. Projeto de Lei $\mathrm{n}^{-0}$ 2.222, de 11 de fevereiro de 1957. Câmara dos Deputados, Brasília, DF, 10 dez. 2006. Disponível em: https://www.camara. leg.br/proposicoesWeb/fichadetramitacao?idProposicao=201132. Acesso em: 14 mar. 2019.

BRAYNER, Flávio. O MCP e a invenção do “povo”. Revista Continente, Recife, ano 10, n. 113, p. 54, 8 maio 2010.

BRAYNER, Flávio. O elixir da Redenção: o Movimento de Cultura Popular do Recife (1960-1964). In: STRECK, Danilo; ESTEBAN, Maria Teresa (org.). 
comunicação \& educação • Ano XXIV • número 1 • jan/jun 2019

Educação popular: lugar de construção social coletiva. Petrópolis: Vozes, 2013. p. 188-202.

BRAYNER, Flávio. Paulofreireanismo: instituindo uma teologia laica? In: REUNIÃO NACIONAL DA ANPED, 37., 2015, Florianópolis. Anais [...]. Rio de Janeiro: Anped, 2015. Trabalho apresentado no GT6.

CADERNOS REGIÃO E EDUCAÇÃO. Recife: Centro Regional de Pesquisas Educacionais do Recife, v. 3, n. 3, jun. 1963.

CENTRO REGIONAL DE PESQUISAS EDUCACIONAIS DO RECIFE. Educação e região: problemas de política e administração escolares no Nordeste brasileiro. Recife: CRPE, 1960.

COELHO, Germano. MCP: história do Movimento de Cultura Popular. Recife: Ed. do Autor, 2012.

EDUCAÇÃO pelo rádio: MCP. Diário de Pernambuco, Recife, n. 154, 9 jul. 1961. Primeiro Caderno, p. 6. Disponível em: http://memoria.bn.br/ DocReader/029033_14/11102. Acesso em: 18 mar. 2019.

EGITO, Juscelino Lima. As primeiras escolas e a formação da rede escolar pública municipal (1894-1929). In: RECIFE. Recife: 100 anos de escola pública municipal. Recife: Prefeitura da Cidade, 2000. p. 26-32.

FÁVERO, Osmar (org.). Cultura popular, educação popular: memória dos anos 60. 2. ed. Rio de Janeiro: Graal, 1983.

FOUCAULT, Michel. A arqueologia do saber. 7. ed. Rio de Janeiro: Forense Universitária, 2009.

FREIRE, Paulo. A propósito de uma administração. Recife: Universidade do Recife, 1961.

FREYRE, Gilberto. Região e tradição. Rio de Janeiro: José Olympio, 1941.

FREYRE, Gilberto. Palavras às professoras rurais do Nordeste. Revista Brasileira de Estudos Pedagógicos, Rio de Janeiro, v. 28, n. 68, p. 40-50, 1957a.

FREYRE, Gilberto. Sugestões para uma nova política no Brasil: a rurbana. Revista Brasileira de Estudos Pedagógicos, Rio de Janeiro, v. 27, n. 65, p. 65-82, $1957 \mathrm{~b}$.

FREYRE, Gilberto. Arte e ciência social e sociedade. Revista Brasileira de Estudos Pedagógicos, Rio de Janeiro, v. 30, n. 72, p. 28-38, 1958a.

FREYRE, Gilberto. Região, pesquisa social e educação. Revista Brasileira de Estudos Pedagógicos, Rio de Janeiro, v. 29, n. 69, p. 31-41, 1958b.

GODOY, Josina; PORTO, Norma. Apêndice. In: MOVIMENTO de Cultura Popular: memorial. Recife: Fundação de Cultura da Cidade do Recife, 1986. (Coleção Recife, v. 49). 
GOMINHO, Zélia. Veneza Americana x Mucambópolis: o Estado Novo na cidade do Recife (décadas de 30 e 40). 1997. Dissertação (Mestrado em História) - Universidade Federal de Pernambuco, Recife, 1997.

INAUGURADAS, ontem, as primeiras 50 escolas radiofônicas no Recife. Diário de Pernambuco, Recife, n. 208, 12 set. 1961. Primeiro Caderno, p. 3. Disponível em: http://memoria.bn.br/DocReader/029033_14/12339. Acesso em: 18 mar. 2019.

JUREMA, Aderbal. A situação do ensino primário em Pernambuco. In: CENTRO REGIONAL DE PESQUISAS EDUCACIONAIS DO RECIFE. Educação e região: problemas de política e administração escolares no Nordeste brasileiro. Recife: CRPE, 1960. p. 67-88.

LIVRO de leitura para adultos. In: MOVIMENTO de Cultura Popular: memorial. Recife: Fundação de Cultura da Cidade do Recife, 1986. (Coleção Recife, v. 49).

MOVIMENTO de Cultura Popular: memorial. Recife: Fundação de Cultura da Cidade do Recife, 1986. (Coleção Recife, v. 49).

NOVAS escolas do MEG e audiência de Arraes nos bairros. Diário de Pernambuco, Recife, n. 69, 25 mar. 1961. Segundo Caderno, p. 3. Disponível em: http://memoria.bn.br/DocReader/029033_14/9117. Acesso em: 18 mar. 2019.

PLANO de educação de adultos, do MCP. Diário de Pernambuco, Recife, n. 22, 26 jan. 1961. Primeiro Caderno, p. 3. Disponível em: http://memoria. bn.br/DocReader/029033_14/8018. Acesso em: 18 mar. 2019.

PRESENÇA na mídia: matérias em jornais ou revistas de divulgação. Biblioteca Virtual Anísio Teixeira, Salvador, [2000?]. Disponível em: http:/ / www.bvanisioteixeira.ufba.br/midia.htm. Acesso em: 14 mar. 2019.

SAVIANI, Dermeval. Escola e democracia. 41. ed. São Paulo: Autores Associados, 2009.

SOUZA, João Francisco de. Uma pedagogia da revolução: a contribuição do governo Arraes (1960-64) à reinvenção da educação brasileira. São Paulo: Cortez: Autores Associados, 1987.

TEIXEIRA, Anísio Spínola. Educação não é privilégio. 7. ed. Rio de Janeiro: Editora UFRJ, 2007.

WEBER, Silke. Política e educação: o Movimento de Cultura Popular no Recife. Revista de Ciências Sociais, Rio de Janeiro, v. 27, n. 2, p. 233-262, 1984. 